2. Genetic counseling. Lubs HA and de la Cruz F ed. New York; Raven Press. 1977

3. Counseling in medical genetics. Reed S. Alan R Liss, Inc. New York, Third Edition, 1980.

4. A genetic counseling casebook. Applebaum EG and Firestein SK. Free Press, Collier
Macmillan Publ. London. 1983

5. Genetic counseling. Fuhrman $\mathbf{H}$ and Vogel $\mathrm{F}$. Springer-Verlag. Third Edition; 1983

6. Psychological aspects of genetic counseling. Emery AEH and Pallen I, ed. London. Academic Press. 1984

\title{
HOME PHOTOTHERAPY
}

Home phototherapy is a feasible and safe alternative to in-hospital phototherapy for carefully selected, otherwise healthy infants, with hyperbilirubinemia as their sole problem. Parents must be capable of following instructions and of assessing when to call their physician regarding problems. Serum bilirubin levels decline as rapidly with home phototherapy as with comparable in-hospital treatment. Physicians must be as vigilant following serial bilirubin levels of infants treated at home as they are with similar hospitalized infants. Costs of home phototherapy are considerably less than those for hospitalization for treatment. The case of breastfeeding at home is an added benefit. However, it should not replace in-hospital phototherapy for infants with multiple problems, inadequate home facilities, or poorly motivated parents.

Criteria for enrollment. Infant $>24 \mathrm{hr}$ postnatal age, infant birth wt $>2,270 \mathrm{~g}$ (5 lbs), physician's assessment that infant's clinical diagnosis and total bilirubin level allowed adequate margin of error for a trial of home phototherapy, parents capable of managing home phototherapy.

Installation checklist. Explain how to position light $16^{\prime \prime}-18^{\prime \prime}$ from baby. Position light in room to avoid drafts i.e. away from windows, heat ducts, etc. Check that all lights are operating. Demonstrate operation of light.

Safety checklist. Demonstrate application of eye covering. Explain that eye covering must be in place while baby is under the light. Explain type of clothing to be worn (diapers only). Explain the importance of taking regular temperature on the baby. Explain the importance of adequate fluid intake to prevent dehydration. Check room temperature and give thermometer. 